Peer problems, bullying involvement, and affective decision-making in adolescence

\author{
Eirini Flouri* \& Efstathios Papachristou*
}

*Department of Psychology and Human Development, UCL Institute of Education, University College London

Correspondence: Eirini Flouri, Department of Psychology and Human Development, UCL Institute of Education, University College London, 25 Woburn Square, London WC1H 0AA, UK. Email: e.flouri@ucl.ac.uk

Acknowledgements: This study was supported by grant ES/N007921/1 from the Economic and Social Research Council. We are grateful to Jonathan Roiser and Sally Palmer for their useful comments. 


\section{Statement of Contribution}

\section{What is already known on this subject?}

- In adults, decision-making deficits and social exclusion or rejection are linked

- In youth, only two studies have explored this link with gambling tasks measuring realworld difficulties in decision-making

- Both studies were cross-sectional and small-scale

\section{What does this study add?}

- We explore this link in adolescence, using a large, general-population longitudinal sample and the Cambridge Gambling Task

- Bullies were more sensitive to reward (or less sensitive to punishment) than those not involved in bullying.

- Male bullies improved over time in risk adjustment, a finding that warrants further research 


\title{
Peer problems, bullying involvement, and affective decision-making in adolescence
}

\begin{abstract}
We investigated, using a cross-lagged design, the longitudinal association of bullying and peer problems with affective decision-making in adolescence (ages 11 and 14 years) in 13,888 participants of the Millennium Cohort Study. Affective decision-making (risk-taking, quality of decision-making, risk adjustment, deliberation time and delay aversion) was measured with the Cambridge Gambling Task, bullying involvement (bully, bully-victim, victim, or 'neutral' status) with self-report measures, and peer problems with the parentreported Strengths and Difficulties Questionnaire. In general, peer problems were associated with decision-making in the unadjusted model but not after controlling for confounding. However, bullying involvement was related to decision-making even after adjustment. Compared to 'neutral' males, bullies and bully-victims improved over time in risk adjustment, and bully-victims in deliberation time, too. In both sexes, bullies showed more risk-taking compared to their 'neutral' counterparts. It seems that bullies are more sensitive to reward (or less sensitive to punishment) than those not involved in bullying. The finding that male bullies show improvement in decision-making warrants further research.
\end{abstract}

Keywords: affective decision making; bullying; gambling task; peer problems; peer victimisation 


\section{Introduction}

Much research has shown that peer problems, such as exclusion or rejection, are very strongly related to mental health difficulties in childhood and adolescence (Arseneault, Bowes, \& Shakoor, 2010; Arseneault et al., 2006; Fekkes, Pijpers, Fredriks, Vogels, \& Verloove-Vanhorick,; Gini \& Pozzoli, 2009). Via their association with stress and depressive symptoms, peer problems can also impair cognitive functioning (Holmes, Kim-Spoon, \& Deater-Deckard, 2016; Vaillancourt et al., 2011) and academic achievement (Buhs, Ladd, \& Herald, 2006). We carried out this study to explore if they are also related to youths' deficits in affective decision-making. According to Bracha and Brown (2012), affective decisionmaking is the strategic process of choice under risk and the result of the interaction between 'rational' and 'emotional' processes (Bracha \& Brown, 2012). Usually measured with gambling tasks, deficits in affective decision-making (henceforth decision-making) are associated with clinical diagnoses, such as substance abuse, attention-deficit/hyperactivity disorder and affective disorders, in both adults (Buelow \& Suhr, 2009) and youth (SonugaBarke, Cortese, Fairchild, \& Stringaris, 2016), but also with risky behaviours, such as smoking, alcohol and drug use, and emotional and behavioural problems. In general, poor decision-making reflecting reward-hyposensitivity and diminished reward-seeking is related to emotional problems (Rawal, Collishaw, Thapar, \& Rice, 2013). Poor decision-making, as reflected in enhanced responses to rewarding outcomes and deficits in the activity of motivational circuitry during anticipation of rewards, is generally related to behavioural problems (Ernst et al., 2003).

Much research with adults to date has suggested or shown that exclusion or rejection impact on decision-making, usually by increasing risk-taking (Buelow, Okdie, Brunell, \& Trost 2015; Buelow \& Wirth, 2017; Jamieson, Koslov, Nock, \& Mendes, 2012). In youth, exclusion or rejection by peers is typically studied in the context of bullying (Godleski, 
Kamper, Ostrov, Hart, \& Blakely-McClure, 2015; Wolke, Woods, Bloomfield, \& Karstadt, 2000), strongly related to health and behaviour in youth. Bullying is a distinct type of aggression in childhood and adolescence, characterised by a repeated and systematic abuse of power (Olweus, 2013). It can encompass both physical and verbal aggressive actions, and can be direct (e.g., hitting) or indirect (e.g., spreading rumours). In children and adolescents, the research into the association between bullying involvement (i.e., bully, victim, bully-victim, or 'neutral' status) and decision-making as measured with gambling tasks is scant with only two studies, both cross-sectional and small-scale, to date exploring this. The first (Poon, 2016), a study with 136 12-17 year olds in Hong Kong tested on the Cambridge Gambling Task (also used in this study; details below) found that bullies and bully-victims showed better risk adjustment (that is, they tended to select higher bets when the chances of winning were favourable, and lower bets when they were unfavourable). Victims, on the other hand, showed less deliberation time and more delay aversion. In the second, a study with 60 10-11 year olds tested on the Iowa Gambling Task (IGT; Medeiros, Torro-Alves, Malloy-Diniz, \& Minervino, 2016), bullies showed a 'myopia for the future' (i.e., a preference for immediate outcomes in favour of delayed ones). However, neither study adjusted for confounders, accounted for any reciprocal relationships between decision-making and bullying - suggested by findings using behavioural measures (Gámez-Guadix, Orue, Smith, \& Calvete, 2013) - or controlled for (or stratified by) sex. Sex is related to bullying (Sawyer, Bradshaw, \& O'Brennan, 2008) and decision-making (Steinberg, 2008; van den Bos, Homberg, \& de Visser, 2013), and likely moderates the association between bullying and decision-making (van den Bos, Harteveld \& Stoop, 2009).

Given that research with adults has shown that experiencing rejection increases rather than reduces risk-taking, the finding by Medeiros et al. (2016) that, among children and early adolescents, bullies rather than victims showed more risk-taking may appear counter- 
intuitive. However, bullying and peer problems are distinct constructs in children (Buhs et al., 2006; Morrow, Hubbard, Barhight, \& Thomson, 2014), with both victims and bullies experiencing peer rejection (Bouman et al., 2012; Veenstra et al., 2005; Salmivalli, 2010). In addition, although both victims and bullies may take risks in order to gain acceptance, presumably the main reason for the increase in risk-taking typically seen after rejection or exclusion, bullies are primarily motivated by the need to establish dominance, a powerful correlate of risk-taking (Anderson \& Galinsky, 2006). This would be in line with much research showing that bullying perpetrators exhibit high levels of behaviourally measured risk-taking in adolescence, including smoking (Morris, Zhang, \& Bondy, 2006), alcohol/drug use (Radliff, Wheaton, Robinson, \& Morris, 2012) and sexual risk behaviour (Holt, Matjasko, Espelage, Reid, \& Koenig, 2013). The finding in Poon's (2016) study that youth who bully show better risk adjustment than those who do not is in line with much research suggesting that bullies can be strategic and therefore flexible in their approach and behaviour (Salmivalli, 2010).

\section{The present study}

Clearly, more research into the association between bullying and decision-making in youth is needed. In addition, the extant research has yet to consider peer problems and bullying jointly. We addressed both issues using longitudinal data from the Millennium Cohort Study (MCS) - a large population-based birth cohort in the UK - and an 'objective' and ecologically valid measure of decision-making, the CGT, which measures reward and punishment sensitivity outside a learning context and under uncertainty. The CGT is considered ecologically valid because performing advantageously on this task requires, as in real life, dealing with uncertainty in a context of punishment and reward: some choices are advantageous in the short-term (high reward) but disadvantageous in the long run (higher punishment) while others are less attractive in the short-term (low reward) but advantageous 
in the long run (lower punishment). Importantly, it is appropriate to use for our purposes because, unlike the IGT, it makes the critical information for each decision (risk, potential gain and potential loss) explicit on each trial. Hence there is no requirement for learning. Thus, a major advantage of the CGT is that it can experimentally quantify risky decisionmaking, betting behaviour, reaction time and adaptation to risk without the need for learning and thus the recruitment of other cognitive resources (Rogers et al., 1999; Deakin, Aitken, Robbins, \& Sahakian, 2004). It additionally separates out two key components of decisionmaking: 1) probabilistic choice - whether participants choose a low or a high probability option, and 2) betting - whether participants place a high or a low stake (see also under Measures below). The CGT is not normed in children or adolescents, although previous studies have used it with both high-risk (Rawal et al., 2013) and clinical (DeVito et al., 2008; Sorensen et al., 2016) youth populations.

Specifically, we explored in this study the role of bullying involvement in decisionmaking as measured by the CGT at the two time-points in adolescence (ages 11 and 14 years) that was available in MCS. We also explored, for the first time, how peer problems may be related to decision-making, and whether type of bullying involvement can interact with peer problems to predict decision-making. Our research expectations were as follows: 1) Peer problems would be related positively to risk-taking and negatively to risk adjustment (Buelow et al., 2015; Buelow \& Wirth, 2017; Jamieson et al., 2012). 2) There would be bidirectional associations too, such that risk-taking and poor risk adjustment would be 'caused by' as well as, in view of the evidence with behavioural measures (Stenseng, Belsky, Skalicka, \& Wichstrøm, 2016), 'cause' peer problems. 3) Bullying involvement would be associated with decision-making (with adolescents who bully in particular showing more risk-taking) (Medeiros et al., 2016; Poon, 2016). 4). Bullying involvement and peer problems would interact, such that adolescents who bully but get rejected by their peers would be more 
risk-taking than those who bully but do not get rejected by their peers. We reasoned that adolescents who bully but get rejected by their peers may feel more strongly that taking risks may help them gain social status, prestige and dominance, compared to adolescents who bully but feel that they have gained peer acceptance.

Analytically, we used a cross-lagged design and we stratified by sex throughout, in view of the sex differences in youth decision-making, peer problems and bullying involvement, as discussed above. We also controlled for variables which are known correlates of bullying involvement, peer problems and decision-making, including: ethnicity (Graham \& Juvonen, 2002; Tippett, Wolke, \& Platt, 2013; Watt, 2005), intelligence (Holmes et al., 2016; Smith, Xiao, \& Bechara, 2012; Verlinden et al., 2014), emotional and behavioural problems (Bubier \& Drabick, 2008; van Lier \& Koot, 2010) and socio-economic disadvantage (Davis et al., 2008; Shetgiri, Lin, Avila, \& Flores, 2012), which, to minimise missingness, we approximated by poverty, maternal education and maternal age. [We considered maternal rather than paternal (or, if applicable, both parents') education because MCS does not follow up non-resident fathers, and so maternal responses were available for the vast majority of the children.]

\section{Methods}

\section{Sample}

MCS is a population-based longitudinal cohort study of children born in the UK over 12 months from 1 September 2000. Children were around 9 months old at Sweep 1, and around 3, 5, 7, 11 and 14 years old at Sweeps 2, 3, 4, 5 and 6, respectively. MCS was designed to over-represent families living in areas of high child poverty, areas with high proportions of ethnic minority populations across England, and the three smaller UK countries. Parent-reported data were collected through interviews and self-completion questionnaires. Ethical approval was gained from NHS Multi-Centre Ethics Committees, and 
parents (and children at Sweeps 5 and 6) gave informed consent before interviews took place. At Sweep 1, 18,522 families participated in MCS. The numbers of productive families at Sweeps 2, 3, 4, 5 and 6 were 15,590, 15,246, 13,857, 13,287 and 11,714, respectively. As explained, MCS has repeated measures of both peer problems and decision-making at Sweeps 5 (age 11) and 6 (age 14) only. The study's analytic sample, therefore, was adolescents (singletons and first-born twins or triplets) with valid data on at least one of these variables in at least one of these two sweeps $(\mathrm{N}=13,888$, of whom 7,032 were male).

\section{Measures}

Decision-making at ages 11 and 14 years was assessed with the Cambridge Gambling Task (CGT; Rogers et al., 1999), as explained. The task was administered in the homes of the cohort members as part of the main interview. On each CGT trial, participants are presented with a row of ten boxes across the top of a computer screen, of which some are red and some are blue. At the bottom of the screen are rectangles containing the words 'Red' and 'Blue'. Participants must guess whether a yellow token is hidden in a red box or a blue box. The task consists of five stages, each of which is a block of trials. In the first, decision-only stage, participants simply have to guess whether the token is hidden under a red or blue box. The latter four stages are gambling stages where, following the colour decision, participants bet a proportion of their points (from an initial 100 on each stage) on their confidence in the location of the yellow token. Two of the gambling stages are practice sessions undertaken prior to a test session, so that participants' performance is ultimately assessed by the two test gambling stages. In the gambling stages, participants start with a number of points displayed on the screen and select a proportion of these points, displayed in either rising or falling order, in a second box on the screen to gamble on their confidence in this judgement. A stake box on the screen displays the current amount of the bet. Participants are informed that correct bets will be added onto their points score (and incorrect ones will be subtracted from 
it) and that they should try to win as many points as possible. The task produces six outcome measures, all of which were examined in this study. Risk-taking is the mean proportion of points bet on trials where the most probable colour was chosen. Therefore, more risk-taking on the CGT indicates higher sensitivity to reward/gain (and/or lower sensitivity to punishment/loss). Quality of decision-making is the mean proportion of trials where the participant selects the most probable colour. Deliberation time is the mean time (in milliseconds) taken to make a box colour response. Risk adjustment is the extent to which betting behaviour is moderated by the ratio of boxes, and reflects the tendency to stake higher bets on favourable compared to unfavourable trials. Delay aversion reflects whether participants are prepared to wait in order to place a higher or lower bet. Overall proportion bet is the mean proportion of points bet across all trials.

Peer problems at ages 11 and 14 years were measured with the peer problems scale of the parent-reported Strengths and Difficulties Questionnaire (SDQ; Goodman, 1997), a reliable, valid and widely used measure of emotional and behavioural problems in children and adolescents (Goodman, Ford, Simmons, Gatward, \& Meltzer, 2000). In our sample, the scale had acceptable internal consistency at both $11(\alpha=0.72)$ and 14 years $(\alpha=0.62)$, and is composed of five items, scored from $0=$ not true to $2=$ certainly true, such as "Rather solitary, tends to play alone" and "Gets on better with adults than with other children".

Bullying involvement at ages 11 and 14 years was based on two self-report items, both scored on six-point scales from $1=$ most days to $6=$ never: "How often do other children hurt you or pick on you on purpose?"; "How often do you hurt or pick on other children on purpose?" Previous research suggests that single items assessing bullying involvement have adequate concurrent validity with multi-item scales, such as the Forms of Bullying Scale (Shaw, Dooley, Cross, Zubrick, \& Waters, 2013). In line with much previous research (Tippett et al., 2013; Veenstra et al., 2005), we specified four mutually exclusive and 
collectively exhaustive groups of bullying involvement at each age: Participants who answered never on both questions were classified as 'neutrals', those answering between ' 1 ' (most days) and ' 5 ' (less often than every few months) on the first and ' 6 ' (never) on the second were classified as 'victims', those answering between ' 1 ' and ' 5 ' on the second and ' 6 ' on the first were classified as 'bullies', and those whose answers on both questions ranged between ' 1 ' and ' 5 ' were classified as 'bully-victims'.

Finally, we adjusted for the following covariates at age 11 years to minimise confounding: maternal age, maternal education (university degree or not), and emotional and behavioural problems, measured with the parent-reported SDQ. On SDQ, behavioural (externalising) problems are assessed with ten items $(\alpha=0.87)$ measuring conduct problems and hyperactivity, and emotional problems are measured with five emotional symptoms $(\alpha=$ 0.77). We also adjusted for ethnicity (white, black, Indian, Pakistani/Bangladeshi, mixed and other), exact age at assessment, poverty (number of sweeps below the poverty line, defined as $60 \%$ of the UK median household income ${ }^{1}$ ), and intelligence, which at age 11 years was measured with the Verbal Similarities test of the British Ability Scales (Elliot, Smith, \& McCulloch, 1996). Children's age-adjusted scores on this scale were transformed into standardised IQ scores with a mean of 100 and a standard deviation of 15.

\section{Analytic approach}

Analyses were performed in Stata/SE 14.2 (StataCorp, 2015) and Mplus 7.4 (Muthén \& Muthén, 1998-2004). First, we examined the associations between decision-making and peer problems at ages 11 and 14 years. We calculated Spearman correlation coefficients to account for the skewed distributions of some of the decision-making measures. Next, we utilised a cross-lagged design to explore the associations between peer problems and decision-making at both ages. The cross-lagged models were run using the maximum

\footnotetext{
${ }^{1}$ We measured number of sweeps in poverty from age 3 years (Sweep 2) not age 9 months (Sweep 1), as Sweep 2 introduced 692 'new families' to MCS, whom we would have lost had we started from Sweep 1.
} 
likelihood with robust standard errors estimator, which is robust to non-normality in the data and can also handle a combination of continuous and categorical observed variables. Model fit was assessed using three fit indices, the Comparative Fit Index (CFI), the Root Mean Square Error of Approximation (RMSEA) and the Standardised Root Mean Square Residual (SRMR). CFI values $>=0.95$, RMSEA values $<0.06$ and SRMR values $<0.05$ are indicative of good model fit (Hooper, Coughlan, \& Mullen, 2008). In the baseline model we estimated simultaneously the associations between peer problems and decision-making over time (cross-lagged paths) as well as the stability of each measure across the two consecutive timepoints (auto-regressive paths). In the next model we further estimated the effect of bullying involvement at age 11 and the interaction between bullying involvement and peer problems at age 11 on decision-making at age 14 . One interaction term was created for each of the bully, bully-victim and victim categories using 'neutral' as the reference group. Finally, in the third model we tested which of these paths survived adjustments for the covariates. All models were stratified by sex. We examined sex differences in the significant paths in the adjusted model using Wald tests. Missing data on the variables included in the models were handled by using the full information maximum likelihood estimator. We also included in the models attrition and non-response sample weights as well as stratification and clustering weights to account for the disproportionately stratified and clustered design of MCS (Plewis, Calderwood, Hawkes, Hughes, \& Joshi, 2007).

\section{Results}

\section{Descriptive statistics and bivariate analyses}

Table 1 presents the main characteristics of the analytic sample at ages 11 and 14 years by sex. At both assessments males scored significantly higher than females in delay aversion, risk-taking and overall proportion bet. At age 14 years they also scored higher in risk adjustment, i.e., they showed fewer difficulties adjusting to changing probabilities of choice 
outcomes. The sex difference in deliberation time changed direction with age, such that males were faster than females at age 11 and slower at age 14 . Males at age 11 years additionally reported having more peer problems, more externalising problems and fewer emotional symptoms, compared to females. With respect to bullying involvement, males were more likely to be bullies ( $72 \%$ and $64 \%$ of all bullies at ages 11 and 14, respectively, were male) compared to females. By contrast, more females (53\% and 58\%, respectively) were victims. The bullying involvement categories showed moderate temporal stability between the two assessments $\left(\chi^{2}(9)=1100\right.$, gamma $\left.=0.29\right)$, suggesting that bullying involvement status in adolescence can vary over time. In terms of the other variables at baseline, there were no sex differences in age, maternal age, maternal education, poverty or ethnicity.

(Table 1)

Table 2 presents the bivariate correlations across the outcome measures. At age 11 years, peer problems correlated weakly, albeit significantly, with all decision-making measures. As expected, there were positive associations between peer problems and delay aversion, deliberation time, overall proportion bet and risk-taking, and negative associations between peer problems and quality of decision-making and risk adjustment. The correlation coefficients (rho) ranged in absolute terms from 0.05 to 0.10 . At age 14 years, peer problems correlated positively with delay aversion $($ rho $=0.03, \mathrm{p}<0.01)$ and deliberation time $($ rho $=$ $0.10, \mathrm{p}<0.01$ ), and negatively with quality of decision-making ( $r h o=-0.07, \mathrm{p}<0.01$ ) and risk adjustment $(r h o=-0.09, \mathrm{p}<0.01)$. Regarding the associations between the decisionmaking measures at each assessment, the relationship between risk-taking and quality of decision-making at age 14 years did not reach statistical significance, while the correlations between risk-taking and overall proportion bet were very high at 0.96 and 0.97 , at ages 11 and 14 years, respectively. The remaining correlation coefficients between the individual decision-making measures at each assessment were statistically significant, ranging in 
absolute terms from 0.04 to 0.47 . In order to avoid multicollinearity, we excluded overall proportion bet from the multivariate analyses and considered only the remaining five decision-making measures.

(Table 2)

Supplementary Tables S1-S2 show the associations of type of bullying involvement with peer problems and decision-making. As can be seen in Table S1, victims and bullyvictims seemed to have more peer problems than 'neutral' adolescents but also bullies. Bullies scored higher in overall proportion bet and risk-taking. Risk adjustment and quality of decision-making did not differ by type of bullying involvement at age 11 . Risk adjustment at age 14, however, was higher for bully-victims and victims, compared to bullies. Quality of decision-making differed by bullying involvement only in females and only at age 14, with bullies scoring lower than the rest. However, when age 11 bullying involvement was explored in conjunction with age 14 decision-making (Table S2) to reflect the approach taken to fit the cross-lagged models, neither risk adjustment at age 14 nor quality of decisionmaking at age 14 differed by type of bullying involvement at age 11 .

\section{Cross-lagged models}

The results of the cross-lagged models are presented in Tables 3-4 and Figure 1. All three cross-lagged models showed good and comparable fit to the data, with CFI, SRMR and RMSEA values ranging from 0.93 to $0.95,0.02$ to 0.03 and 0.03 to 0.05 , respectively. The baseline cross-lagged model showed that, in both males and females, peer problems raised delay aversion and deliberation time and reduced risk adjustment and quality of decisionmaking (Table 3). The relationship between peer problems and decision-making was bidirectional only for risk adjustment; no other decision-making variable at age 11 was related to peer problems at age 14 (Table 4) after controlling for peer problems at age 11. 
In the next two models we examined the effect of bullying involvement as well as the interaction between bullying involvement and peer problems on later decision-making, with and without adjustment for confounders. As can be seen in Table 3, the negative association between peer problems and subsequent risk adjustment (like the one between peer problems and quality of decision-making in females) was significant even after controlling for bullying involvement and the interaction between bullying involvement and peer problems (Model B). As can be seen in Figure 1 which presents the significant regression paths after full adjustment (Model C), all autoregressive paths were significant and ranged from 0.13 to 0.50 suggesting moderate stability of the measures across the two assessments. No cross-lagged paths were significant. Even after full adjustment, bullying involvement was significant in predicting changes in decision-making, although it appeared to do so mainly in males. Compared to 'neutral' males, male bully-victims showed increased risk adjustment and reduced deliberation time. Male bullies also showed increased risk adjustment, whereas both male and female bullies showed increased risk-taking. The results of Wald tests examining sex differences in the magnitude of associations between bullying involvement with decisionmaking and peer problems showed that the effect of bully-victim status on deliberation time $(\mathrm{p}=0.02)$ and that of bully status on risk-taking $(\mathrm{p}=0.05)$ were significantly stronger for males compared to females - albeit the latter one marginally.

\section{(Tables 3-4 and Figure 1)}

With respect to the effects of the interaction terms, only bully status interacted significantly with peer problems for risk-taking and delay aversion among females: females who at age 11 bullied and had peer problems reduced in risk-taking and delay aversion at age 14, compared to their counterparts who bullied but did not have peer problems (Model C). Given that interaction tests with bully status in females in our sample are likely very 
underpowered (only 122 out of the total 6,375 females at age 11 with valid data on bullying involvement were classified as bullies), we must treat these interactions as exploratory.

\section{Discussion}

We carried out this study to explore in a large population-based cohort in the UK the associations of decision-making in adolescence (at ages 11 and 14 years) with peer problems and bullying involvement. We found that peer problems were associated with increased deliberation time and delay aversion from age 11 to age 14 years. They were also associated with reduced risk adjustment and quality of decision-making over this period. However, with the exception of the relationship between peer problems and risk adjustment (and that between peer problems and quality of decision-making in females), these associations were attenuated after controlling for bullying involvement. Importantly, even after taking bullying involvement into account, the association between risk adjustment and peer problems was bidirectional, such that risk adjustment and peer problems reciprocally reduced one another. Both longitudinal relationships between risk adjustment and peer problems became nonsignificant however after adjusting for confounding (via controlling for emotional and

behavioural problems, intelligence, ethnicity and socio-economic disadvantage). The effect of peer problems on quality of decision-making in females also became nonsignificant in the full model.

By contrast, bullying involvement was associated with changes in decision-making, even after full adjustment for confounding. Compared to 'neutral' adolescents, both male and female bullies showed increased risk-taking, suggesting, in line with previous research (Medeiros et al., 2016), that bullies tend to be more sensitive to reward. Among males, both bullies and bully-victims also showed improvement in risk adjustment, and bully-victims in deliberation time, too. Why do we see this improvement in decision-making among males 
who bully? We think that these findings converge with others (Olthof, Goossens, Vermande, Aleva, \& van der Meulen, 2011; Reijntjes et al., 2013) to support the view that bullying is strategic behaviour. According to this, bullies, like all human beings, are driven by considerations of both status and affection (Lindenberg, 2001). This in turn means that bullies, who, by definition, are driven first by the desire to dominate, will seek opportunities to do so without risking loss of affection from significant others. Thus, in childhood and adolescence, bullies (especially instrumental or proactive as opposed to reactive bullies) likely divide the peer group into potential sources of affection (significant others) and potential sources of domination (victims for whom the significant others do not care) and choose victims who are already rejected or disliked by significant others in the group (Veenstra, Lindenberg, Munniksma, \& Dijkstra, 2010). Our findings however go beyond this. They show that bullies improved their 'strategic thinking' over time. If this association is causal, it suggests that the very experience of bullying others is associated with such benefits for the individual, at the expense of others. But why was this presumably improved strategic thinking associated with bullying perpetration not seen in females in our sample? We think that this may be because proactive bullying, the type that is apparently strategic and thus likely associated with affective decision-making, is used more frequently by males compared to females (Pellegrini \& Long, 2002) and comes at a cost in females (Manring, Elledge, Swails, \& Vernberg, 2017; Olthof \& Goossens, 2008).

Overall, our findings are in line with previous evidence from the few other studies measuring affective decision-making with gambling tasks that adolescents who bully are sensitive to reward (Medeiros et al., 2016; Poon, 2016). They also show that male bullies show improvement in decision-making. Both associations appear to be robust since they survived our adjustment for emotional and behavioural problems, intelligence, ethnicity, socio-economic disadvantage and, importantly, prior levels of decision-making. Strategies 
aiming to identify bullying behaviour in schools and interventions aiming to prevent it should take these findings into consideration. Accordingly, a priority for future research should be an in-depth investigation of the reasons why adolescents who bully are more sensitive to reward (or less sensitive to punishment). Testing for shared genetic aetiology could probably be the first step. The impact of the duration of bullying should also be examined as it is likely that, irrespective of the nature of the association between bullying and sensitivity to reward, chronic and transient bullying are aetiologically distinct. Genetic data combined with epidemiological exposure data should provide optimal ground for such endeavours.

\section{Strengths and limitations}

Our study has many strengths. It used data from the largest UK birth cohort and controlled for various confounders to study the associations between bullying involvement, affective decision-making and peer problems in adolescence. Nonetheless its findings should be interpreted in light of several limitations. First, our study could not differentiate between different types of bullying (e.g., indirect or direct), related differently to strategic considerations and sex (and their interaction; Pellegrini, 2003). Second, it assessed bullying involvement by two self-report measures, which likely underestimate the prevalence of bullying and victimisation but also likely introduce social desirability and retrospective recall biases. Future research should address both these limitations by including, for example, detailed information on type of bullying and using peer nominations and behavioural observations as supplementary measures. Third, it did not take into account bullying at younger ages. Bullying and victimisation are already common problems in early primary school (Jansen et al., 2012) but we cannot know if the associations found in our study hold for younger ages too, or whether they may be moderated by the timing and/or the duration of bullying involvement. Fourth, some of the interactions between peer problems and bullying involvement that we tested in our analyses are likely underpowered due to the small number 
of participants in some of the categories, such as the 'bully' group among females. Finally, there are the limitations of the CGT. Risk-taking conflates the seeking of reward and the avoidance of punishment. Reduced betting, even when the odds of winning are high, might occur because participants are less motivated by reward or because they want to avoid losing (punishment), and this cannot be disentangled in this task.

In conclusion, our study found that adolescents who bully others are more sensitive to reward (or less sensitive to punishment) than adolescents not involved in bullying. It also showed that, among males, the experience of bullying others was associated with an improvement in decision-making. The latter finding especially warrants further research. 


\section{References}

Anderson, C., \& Galinsky, A. D. (2006). Power, optimism, and risk- taking. European Journal of Social Psychology, 36, 511-536. http://dx.doi.org/10.1002/ejsp.324

Arseneault, L., Bowes, L., \& Shakoor, S. (2010). Bullying victimization in youths and mental health problems: 'Much ado about nothing'?. Psychological Medicine, 40, 717-729. http://dx.doi.org/10.1017/S0033291709991383

Arseneault, L., Walsh, E., Trzesniewski, K., Newcombe, R., Caspi, A., \& Moffitt, T. E. (2006). Bullying victimization uniquely contributes to adjustment problems in young children: a nationally representative cohort study. Pediatrics, 118, 130-138. http://dx.doi.org/10.1542/peds.2005-2388

Bouman, T., van der Meulen, M., Goossens, F. A., Olthof, T., Vermande, M. M., \& Aleva, E. A. (2012). Peer and self-reports of victimization and bullying: Their differential association with internalizing problems and social adjustment. Journal of School Psychology, 50, 759-774. http://dx.doi.org/10.1016/j.jsp.2012.08.004

Bracha, A., \& Brown, D. J. (2012). Affective decision making: A theory of optimism bias. Games and Economic Behavior, 75, 67-80. https://doi.org/10.1016/j.geb.2011.11.004

Bubier, J. L., \& Drabick, D. A. (2008). Affective decision-making and externalizing behaviors: The role of autonomic activity. Journal of Abnormal Child Psychology, 36, 941-953. http://dx.doi.org/10.1007/s10802-008-9225-9

Buelow, M. T., Okdie, B. M., Brunell, A. B., \& Trost, Z. (2015). Stuck in a moment and you cannot get out of it: The lingering effects of ostracism on cognition and satisfaction of basic needs. Personality and Individual Differences, 76, 39-43. http://dx.doi.org/10.1016/j.paid.2014.11.051

Buelow, M. T., \& Suhr, J. A. (2009). Construct validity of the Iowa gambling task. Neuropsychology Review, 19, 102-114. http://dx.doi.org/10.1007/s11065-009-9083-4 
Buelow, M. T., \& Wirth, J. H. (2017). Decisions in the face of known risks: Ostracism increases risky decision-making. Journal of Experimental Social Psychology, 69, 210217. https://doi.org/10.1016/j.jesp.2016.07.006

Buhs, E. S., Ladd, G. W., \& Herald, S. L. (2006). Peer exclusion and victimization: Processes that mediate the relation between peer group rejection and children's classroom engagement and achievement?. Journal of Educational Psychology, 98, 1-13. http://dx.doi.org/10.1037/0022-0663.98.1.1

Davis, C., Fox, J., Patte, K., Curtis, C., Strimas, R., Reid, C., \& McCool, C. (2008). Education level moderates learning on two versions of the Iowa Gambling Task. Journal of the International Neuropsychological Society, 14, 1063-1068. http://dx.doi.org/10.1017/S1355617708081204

Deakin, J., Aitken, M., Robbins, T., \& Sahakian, B. J. (2004). Risk taking during decisionmaking in normal volunteers changes with age. Journal of the International Neuropsychological Society, 10, 590-598. https://doi.org/10.1017/S1355617704104104

DeVito, E. E., Blackwell, A. D., Kent, L., Ersche, K. D., Clark, L., Salmond, C. H., ... Sahakian, B. J. (2008). The effects of methylphenidate on decision making in attentiondeficit/hyperactivity disorder. Biological Psychiatry, 64, 636-639. http://dx.doi.org/10.1016/j.biopsych.2008.04.017

Elliott, C. D., Smith, P., \& McCulloch, K. (1996). British Ability Scales Second Edition (BAS II). Administration and scoring manual. London: Nelson.

Ernst, M., Grant, S. J., London, E. D., Contoreggi, C. S., Kimes, A. S., \& Spurgeon, L. (2003). Decision making in adolescents with behavior disorders and adults with substance abuse. American Journal of Psychiatry, 160, 33-40. https://doi.org/10.1176/appi.ajp.160.1.33 
Fekkes, M., Pijpers, F. I., Fredriks, A. M., Vogels, T., \& Verloove-Vanhorick, S. P. (2006). Do bullied children get ill, or do ill children get bullied? A prospective cohort study on the relationship between bullying and health-related symptoms. Pediatrics, 117, 15681574. http://dx.doi.org/10.1542/peds.2005-0187

Gámez-Guadix, M., Orue, I., Smith, P. K., \& Calvete, E. (2013). Longitudinal and reciprocal relations of cyberbullying with depression, substance use, and problematic internet use among adolescents. Journal of Adolescent Health, 53, 446-452.

http://dx.doi.org/10.1016/j.jadohealth.2013.03.030

Gini, G., \& Pozzoli, T. (2009). Association between bullying and psychosomatic problems: A meta-analysis. Pediatrics, 123, 1059-1065. http://dx.doi.org/10.1542/peds.2008-1215

Godleski, S. A., Kamper, K. E., Ostrov, J. M., Hart, E. J., \& Blakely-McClure, S. J. (2015). Peer victimization and peer rejection during early childhood. Journal of Clinical Child \& Adolescent Psychology, 44, 380-392. http://dx.doi.org/10.1080/15374416.2014.940622

Goodman, R. (1997). The Strengths and Difficulties Questionnaire: A research note. Journal of Child Psychology and Psychiatry, 38, 581-586. http://dx.doi.org/10.1111/j.1469-7610.1997.tb01545.x

Goodman, R., Ford, T., Simmons, H., Gatward, R., \& Meltzer, H. (2000). Using the Strengths and Difficulties Questionnaire (SDQ) to screen for child psychiatric disorders in a community sample. The British Journal of Psychiatry, 177(6), 534-539. https://doi.org/10.1192/bjp.177.6.534

Graham, S., \& Juvonen, J. (2002). Ethnicity, peer harassment, and adjustment in middle school: An exploratory study. The Journal of Early Adolescence, 22, 173-199. https://doi.org/10.1177/0272431602022002003 
Holmes, C. J., Kim-Spoon, J., \& Deater-Deckard, K. (2016). Linking executive function and peer problems from early childhood through middle adolescence. Journal of Abnormal Child Psychology, 44, 31-42. http://dx.doi.org/10.1007/s10802-015-0044-5

Holt, M. K., Matjasko, J. L., Espelage, D., Reid, G., \& Koenig, B. (2013). Sexual risk taking and bullying among adolescents. Pediatrics, 132, 1481-1487. https://doi.org/10.1542/peds.2013-0401

Hooper, D., Coughlan, J., \& Mullen, M. (2008). Structural equation modelling: Guidelines for determining model fit. Journal of Business Research Methods, 6, 53-60.

Jamieson, J. P., Koslov, K., Nock, M. K., \& Mendes, W. B. (2012). Experiencing discrimination increases risk taking. Psychological Science, 24, 131-139. http://dx.doi.org/10.1177/0956797612448194

Lindenberg, S. (2001). Social rationality versus rational egoism. In I. H. Turner (Ed.), Handbook of sociological theory (pp. 635-668). New York: Plenum. http://dx.doi.org/10.1007/0-387-36274-6_29

Jansen, P. W., Verlinden, M., Dommisse-van Berkel, A., Mieloo, C., van der Ende, J., Veenstra, R., ... Tiemeier, H. (2012). Prevalence of bullying and victimization among children in early elementary school: Do family and school neighbourhood socioeconomic status matter?. BMC Public Health, 12, 494. https://doi.org/10.1186/1471-2458-12-494

Manring, S., Elledge, L. C., Swails, L. W., \& Vernberg, E. M. (2017). Functions of aggression and peer victimization in elementary school children: The mediating role of social preference. Journal of Abnormal Child Psychology, 46, 795-809. http://dx.doi.org/10.1007/s10802-017-0328-z 
Medeiros, W., Torro-Alves, N., Malloy-Diniz, L. F., \& Minervino, C. M. (2016). Executive functions in children who experience bullying situations. Frontiers in Psychology, 7, 1197. http://dx.doi.org/10.3389/fpsyg.2016.01197

Morris, E. B., Zhang, B., \& Bondy, S. J. (2006). Bullying and smoking: examining the relationships in Ontario adolescents. Journal of School Health, 76, 465-470. https://doi.org/10.1111/j.1746-1561.2006.00143.x

Morrow, M. T., Hubbard, J. A., Barhight, L. J., \& Thomson, A. K. (2014). Fifth-grade children's daily experiences of peer victimization and negative emotions: Moderating effects of sex and peer rejection. Journal of Abnormal Child Psychology, 42, 10891102. http://dx.doi.org/10.1007/s10802-014-9870-0

Muthén, L. K., \& Muthén, B. O. (1998-2004). Mplus users guide (3rd ed.). Los Angeles: Author.

Olthof, T. \& Goossens. F. A. (2008). Bullying and the need to belong: Early adolescents' bullying-related behavior and the acceptance they desire and receive from particular classmates. Social Development, 17, 24-46. http://dx.doi.org/10.1111/j.14679507.2007.00413.x

Olthof, T., Goossens, F. A., Vermande, M. M., Aleva, E. A., \& van der Meulen, M. (2011). Bullying as strategic behavior: Relations with desired and acquired dominance in the peer group. Journal of School Psychology, 49, 339-359. http://dx.doi.org/10.1016/j.jsp.2011.03.003

Olweus, D. (2013). School bullying: Development and some important challenges. Annual Review of Clinical Psychology, 9, 751-780. http://dx.doi.org/10.1146/annurev-clinpsy050212-185516

Pellegrini A. (2003). Perceptions and functions of play and real fighting in early adolescence. Child Development, 74, 1522-1533. http://dx.doi.org/10.1111/1467-8624.00620 
Pellegrini, A. D., \& Long, J. D. (2002). A longitudinal study of bullying, dominance, and victimization during the transition from primary school through secondary school. British Journal of Developmental Psychology, 20, 259-280. http://dx.doi.org/10.1348/026151002166442

Plewis, I., Calderwood, L., Hawkes, D., Hughes, G., \& Joshi, H. (2007). Millennium Cohort Study: technical report on sampling. London: Centre for Longitudinal Studies, Institute of Education.

Poon, K. (2016). Understanding risk-taking behavior in bullies, victims, and bully victims using cognitive- and emotion-focused approaches. Frontiers in Psychology, 7, 1838. http://dx.doi.org/10.3389/fpsyg.2016.01838

Radliff, K. M., Wheaton, J. E., Robinson, K., \& Morris, J. (2012). Illuminating the relationship between bullying and substance use among middle and high school youth. Addictive Behaviors, 37, 569-572. https://doi.org/10.1016/j.addbeh.2012.01.001

Rawal, A., Collishaw, S., Thapar, A., \& Rice, F. (2013). 'The risks of playing it safe': A prospective longitudinal study of response to reward in the adolescent offspring of depressed parents. Psychological Medicine, 43, 27-38. http://dx.doi.org/10.1017/S0033291712001158

Reijntjes, A., Vermande, M., Olthof, T., Goossens, F. A., Van De Schoot, R., Aleva, L., \& Van Der Meulen, M. (2013). Costs and benefits of bullying in the context of the peer group: A three wave longitudinal analysis. Journal of Abnormal Child Psychology, 41, 1217-1229. http://dx.doi.org/10.1007/s10802-013-9759-3

Rogers, R. D., Owen, A. M., Middleton, H. C., Williams, E. J., Pickard, J. D., Sahakian, B. J., \& Robbins, T. W. (1999). Choosing between small, likely rewards and large, unlikely rewards activates inferior and orbital prefrontal cortex. Journal of Neuroscience, 19, 9029-9038. https://doi.org/10.1523/JNEUROSCI.19-20-09029.1999 
Salmivalli, C. (2010). Bullying and the peer group: A review. Aggression and Violent Behavior, 15, 112-120. https://doi.org/10.1016/j.avb.2009.08.007

Sawyer, A. L., Bradshaw, C. P., \& O'Brennan, L. M. (2008). Examining ethnic, gender, and developmental differences in the way children report being a victim of "bullying" on self-report measures. Journal of Adolescent Health, 43, 106-114. http://dx.doi.org/10.1016/j.jadohealth.2007.12.011

Shaw, T., Dooley, J. J., Cross, D., Zubrick, S. R., \& Waters, S. (2013). The Forms of Bullying Scale (FBS): Validity and reliability estimates for a measure of bullying victimization and perpetration in adolescence. Psychological assessment, 25, 10451067. http://dx.doi.org/10.1037/a0032955

Shetgiri, R., Lin, H., Avila, R. M., \& Flores, G. (2012). Parental characteristics associated with bullying perpetration in US children aged 10 to 17 years. American Journal of Public Health, 102, 2280-2286. http://dx.doi.org/10.2105/AJPH.2012.300725

Smith, D. G., Xiao, L., \& Bechara, A. (2012). Decision making in children and adolescents: Impaired Iowa Gambling Task performance in early adolescence. Developmental Psychology, 48, 1180-1187. http://dx.doi.org/10.1037/a0026342

Sonuga-Barke, E. J., Cortese, S., Fairchild, G., \& Stringaris, A. (2016). Annual Research Review: Transdiagnostic neuroscience of child and adolescent mental disorders differentiating decision making in attention- deficit/hyperactivity disorder, conduct disorder, depression, and anxiety. Journal of Child Psychology and Psychiatry, 57, 321-349. http://dx.doi.org/10.1111/jcpp.12496

Sorensen, L., Sonuga-Barke, E., Eichele, H., van Wageningen, H., Wollschlaeger, D., \& Plessen, K. J. (2016). Suboptimal decision making by children with ADHD in the face of risk: Poor risk adjustment and delay aversion rather than general proneness to taking risks. Neuropsychology, 31, 119-128. http://dx.doi.org/10.1037/neu0000297 
StataCorp. 2015. Stata Statistical Software: Release 14. College Station, TX: StataCorp

Steinberg, L. (2008). A social neuroscience perspective on adolescent risk-taking.

Developmental Review, 28, 78-106. http://dx.doi.org/10.1016/j.dr.2007.08.002

Stenseng, F., Belsky, J., Skalicka, V., \& Wichstrøm, L. (2016). Peer rejection and attention deficit hyperactivity disorder symptoms: Reciprocal relations through ages 4, 6, and 8 . Child Development, 87, 365-373. http://dx.doi.org/10.1111/cdev.12471

Tippett, N., Wolke, D., \& Platt, L. (2013). Ethnicity and bullying involvement in a national UK youth sample. Journal of Adolescence, 36, 639-649. http://dx.doi.org/10.1016/j.adolescence.2013.03.013

Vaillancourt, T., Duku, E., Becker, S., Schmidt, L. A., Nicol, J., Muir, C., \& MacMillan, H. (2011). Peer victimization, depressive symptoms, and high salivary cortisol predict poorer memory in children. Brain and Cognition, 77, 191-199.

http://dx.doi.org/10.1016/j.bandc.2011.06.012

van den Bos, R., Harteveld, M., \& Stoop, H. (2009). Stress and decision-making in humans: performance is related to cortisol reactivity, albeit differently in men and women. Psychoneuroendocrinology, 34, 1449-1458. http://dx.doi.org/10.1016/j.psyneuen.2009.04.016 van den Bos, R., Homberg, J., \& de Visser, L. (2013). A critical review of sex differences in decision-making tasks: Focus on the Iowa Gambling Task. Behavioural Brain Research, 238, 95-108. http://dx.doi.org/10.1016/j.bbr.2012.10.002

van Lier, P. A., \& Koot, H. M. (2010). Developmental cascades of peer relations and symptoms of externalizing and internalizing problems from kindergarten to fourthgrade elementary school. Development and Psychopathology, 22, 569-582. http://dx.doi.org/10.1017/S0954579410000283 
Veenstra, R., Lindenberg, S., Munniksma, A., \& Dijkstra, J. K. (2010). The complex relation between bullying, victimization, acceptance, and rejection: Giving special attention to status, affection, and sex differences. Child Development, 81, 480-486.

http://dx.doi.org/10.1111/j.1467-8624.2009.01411.x

Veenstra, R., Lindenberg, S., Oldehinkel, A. J., De Winter, A. F., Verhulst, F. C., \& Ormel, J. (2005). Bullying and victimization in elementary schools: A comparison of bullies, victims, bully/victims, and uninvolved preadolescents. Developmental Psychology, 41, 672-682. http://dx.doi.org/10.1037/0012-1649.41.4.672

Verlinden, M., Veenstra, R., Ghassabian, A., Jansen, P. W., Hofman, A., Jaddoe, V. W., ... Tiemeier, H. (2014). Executive functioning and non-verbal intelligence as predictors of bullying in early elementary school. Journal of Abnormal Child Psychology, 42, 953966. http://dx.doi.org/10.1007/s10802-013-9832-y

Watt, T. T. (2005). Race/ethnic differences in alcohol abuse among youth: An examination of risk-taking attitudes as a mediating factor. Journal of Ethnicity in Substance Abuse, 3, 33-47. https://doi.org/10.1300/J233v03n03_03

Wolke, D., Woods, S., Bloomfield, L., \& Karstadt, L. (2000). The association between direct and relational bullying and behaviour problems among primary school children. Journal of Child Psychology and Psychiatry, 41, 989-1002. http://dx.doi.org/10.1111/1469-7610.00687 
Table 1

Unweighted baseline (age 11) and follow-up (age 14) characteristics by sex

Age $11 \quad$ Age 14

$\begin{array}{llllll}\text { Males } & \text { Females } & \mathbf{p} & \text { Males } & \text { Females } & \text { p }\end{array}$

\section{Decision-making}

Delay aversion
Deliberation time
Overall proportion bet
Quality of decision-making
Risk adjustment
Risk-taking
Peer problems

$\begin{array}{cccccc}0.31(0.03) & 0.26(0.00) & <0.001 & 0.28(0.00) & 0.26(0.00) & 0.001 \\ 3262.40(16.08) & 3402.66(17.91) & <0.001 & 2363.14(13.30) & 2315.60(12.58) & 0.01 \\ 0.53(0.00) & 0.45(0.00) & <0.001 & 0.51(0.01) & 0.45(0.01) & <0.001 \\ 0.80(0.00) & 0.80(0.00) & 0.11 & 0.88(0.00) & 0.88(0.00) & 0.99 \\ 0.66(0.01) & 0.63(0.01) & 0.12 & 1.08(0.01) & 0.90(0.01) & <0.001 \\ 0.58(0.00) & 0.48(0.00) & <0.001 & 0.56(0.00) & 0.48(0.00) & <0.001 \\ 1.47(0.02) & 1.28(0.02) & <0.001 & 1.83(0.02) & 1.65(0.02) & <0.001\end{array}$

\section{Bullying involvement}

Neutral, n (\%)
Bully, n (\%)
Bully-victim, n (\%)
Victim, n (\%)
Covariates at age 11

\begin{tabular}{lccc}
\hline Externalising problems & $5.11(0.05)$ & $3.91(0.04)$ & $<0.001$ \\
Emotional problems & $1.80(0.02)$ & $1.94(0.03)$ & $<0.001$ \\
Age & $10.68(0.01)$ & $10.67(0.01)$ & 0.48 \\
Mother's age & $40.11(0.07)$ & $40.15(0.07)$ & 0.76 \\
IQ & $100.53(0.19)$ & $99.47(0.18)$ & $<0.001$ \\
Number of sweeps in & $0.99(0.02)$ & $1.03(0.02)$ & 0.16 \\
poverty & & & \\
Ethnicity & & & \\
White, $\mathrm{n}(\%)$ & $5,561(51 \%)$ & $5,424(49 \%)$ & \\
Mixed, n $(\%)$ & $187(48 \%)$ & $200(52 \%)$ & \\
Indian, n $(\%)$ & $179(53 \%)$ & $161(47 \%)$ &
\end{tabular}


Pakistani/Bangladeshi, n (\%) $\quad 459(49 \%) \quad 486(51 \%)$

Black, n (\%) $223(52 \%) \quad 208(48 \%)$

Other, n $(\%) \quad 95(51 \%) \quad 90(49 \%)$

Mother is university-

educated

$1,161(50 \%) \quad 1,172(50 \%) \quad 0.47$ 
Table 2

Spearman correlation coefficients for the associations between the main study variables at ages 11 and 14

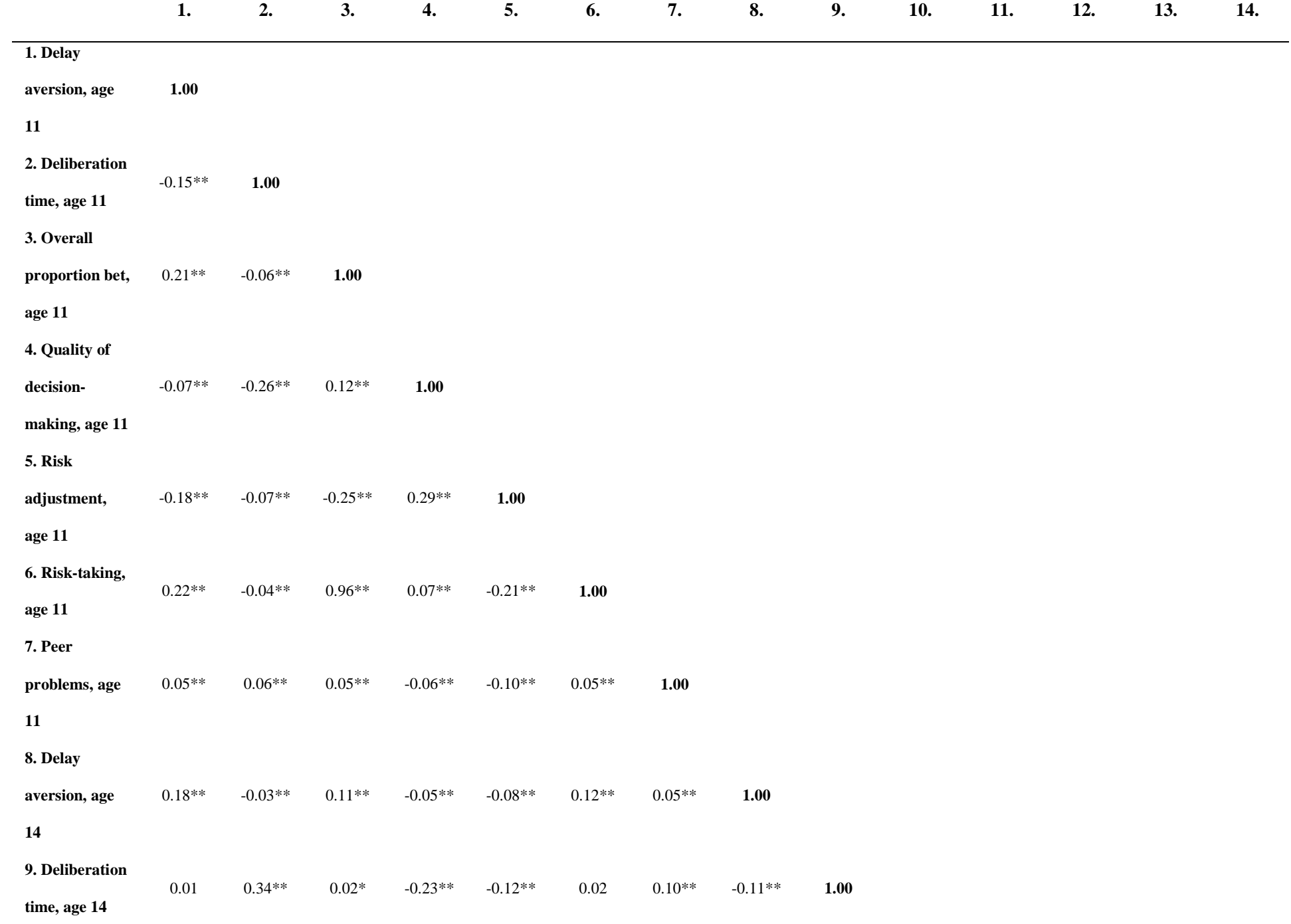




\section{Overall}

proportion bet $-0.08 * *-0.03 * *-0.32 * *-0.02-0.05 * * \quad 0.32 * *-0.01$

age 14

11. Quality of

decision-

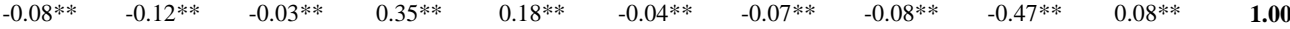

making, age 14

12. Risk

adjustmen

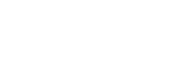

age 14

13. Risk-

taking, age 14

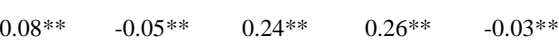

$-0.10^{* *}$

$-0.21^{* *}$

$-0.24 * *$

$-0.25^{* *}$

$0.39 * *$

1.00

14. Peer

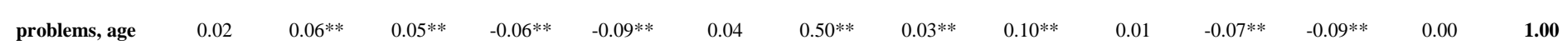

14

$* * \mathrm{p}<0.01$ 
Table 3

Regression paths [unstandardised coefficients (standard errors)] to CGT decision-making variables at age 14 from peer problems, bullying involvement and their interactions at age 11 Risk-taking Delay aversion

Deliberation time Quality of decision-making

Risk adjustment

\begin{tabular}{|c|c|c|c|c|c|c|c|c|c|c|c|c|c|c|c|}
\hline Males & Model A & Model B & Model C & Model A & Model B & Model C & Model A & Model B & Model C & Model A & Model B & Model C & Model A & Model B & Model C \\
\hline Peer problems & $0.00(0.00)$ & $\begin{array}{l}-0.00 \\
(0.00)\end{array}$ & $\begin{array}{l}-0.01 \\
(0.00)\end{array}$ & $\begin{array}{c}0.01 \\
(0.00)^{* *}\end{array}$ & $\begin{array}{c}0.00 \\
(0.00)\end{array}$ & $\begin{array}{l}-0.00 \\
(0.01)\end{array}$ & $\begin{array}{c}0.04 \\
(0.01)^{* *}\end{array}$ & $\begin{array}{c}0.03 \\
(0.02)\end{array}$ & $\begin{array}{c}0.01 \\
(0.02)\end{array}$ & $\begin{array}{c}-0.01 \\
(0.00)^{* *}\end{array}$ & $\begin{array}{l}-0.01 \\
(0.00)\end{array}$ & $\begin{array}{l}-0.00 \\
(0.00)\end{array}$ & $\begin{array}{c}-0.05 \\
(0.01)^{* *}\end{array}$ & $\begin{array}{c}-0.06 \\
(0.03)^{* *}\end{array}$ & $\begin{array}{l}-0.02 \\
(0.02)\end{array}$ \\
\hline $\begin{array}{l}\text { Bullying } \\
\text { involvement }^{a}\end{array}$ & & & & & & & & & & & & & & & \\
\hline Bully & --- & $\begin{array}{c}0.03 \\
(0.01)^{*}\end{array}$ & $\begin{array}{c}0.03 \\
(0.01)^{*}\end{array}$ & --- & $\begin{array}{l}-0.01 \\
(0.02)\end{array}$ & $\begin{array}{l}-0.01 \\
(0.02)\end{array}$ & --- & $\begin{array}{l}0.01 \\
(0.10)\end{array}$ & $\begin{array}{l}-0.01 \\
(0.10)\end{array}$ & --- & $\begin{array}{l}-0.01 \\
(0.01)\end{array}$ & $\begin{array}{l}-0.00 \\
(0.01)\end{array}$ & --- & $\begin{array}{l}0.19 \\
(0.10)\end{array}$ & $\begin{array}{l}0.23^{*} \\
(0.10)\end{array}$ \\
\hline Bully-victim & --- & $\begin{array}{c}0.00 \\
(0.01)\end{array}$ & $\begin{array}{c}0.00 \\
(0.01)\end{array}$ & --- & $\begin{array}{l}0.01 \\
(0.01)\end{array}$ & $\begin{array}{c}0.01 \\
(0.01)\end{array}$ & --- & $\begin{array}{c}-0.16 \\
(0.05)^{* *}\end{array}$ & $\begin{array}{c}-0.14 \\
(0.05)^{* *}\end{array}$ & --- & $\begin{array}{c}0.01 \\
(0.01)\end{array}$ & $\begin{array}{c}0.00 \\
(0.01)\end{array}$ & --- & $\begin{array}{c}0.14 \\
(0.05)^{* *}\end{array}$ & $\begin{array}{c}0.10 \\
(0.05)^{*}\end{array}$ \\
\hline Victim & --- & $\begin{array}{l}-0.01 \\
(0.01)\end{array}$ & $\begin{array}{l}-0.00 \\
(0.01)\end{array}$ & --- & $\begin{array}{l}-0.01 \\
(0.01)\end{array}$ & $\begin{array}{l}-0.01 \\
(0.01)\end{array}$ & --- & $\begin{array}{c}0.00 \\
(0.06)\end{array}$ & $\begin{array}{l}-0.03 \\
(0.06)\end{array}$ & --- & $\begin{array}{c}0.00 \\
(0.01)\end{array}$ & $\begin{array}{l}-0.01 \\
(0.01)\end{array}$ & --- & $\begin{array}{c}0.11 \\
(0.05)^{*}\end{array}$ & $\begin{array}{c}0.05 \\
(0.05)\end{array}$ \\
\hline Interaction terms & & & & & & & & & & & & & & & \\
\hline $\begin{array}{l}\text { Bully*Peer } \\
\text { problems }\end{array}$ & --- & $\begin{array}{l}-0.01 \\
(0.01)\end{array}$ & $\begin{array}{l}-0.01 \\
(0.01)\end{array}$ & --- & $\begin{array}{l}-0.00 \\
(0.01)\end{array}$ & $\begin{array}{l}-0.01 \\
(0.01)\end{array}$ & --- & $\begin{array}{c}0.00 \\
(0.05)\end{array}$ & $\begin{array}{c}0.00 \\
(0.05)\end{array}$ & --- & $\begin{array}{l}0.01 \\
(0.01)\end{array}$ & $\begin{array}{c}0.01 \\
(0.01)\end{array}$ & --- & $\begin{array}{l}-0.03 \\
(0.04)\end{array}$ & $\begin{array}{l}-0.02 \\
(0.04)\end{array}$ \\
\hline $\begin{array}{l}\text { Bully-victim*Peer } \\
\text { problems }\end{array}$ & --- & $\begin{array}{c}0.00 \\
(0.01)\end{array}$ & $\begin{array}{c}0.00 \\
(0.01)\end{array}$ & -- & $\begin{array}{l}0.01 \\
(0.01)\end{array}$ & $\begin{array}{l}0.01 \\
(0.01)\end{array}$ & --- & $\begin{array}{l}0.03 \\
(0.03)\end{array}$ & $\begin{array}{l}0.02 \\
(0.03)\end{array}$ & -- & $\begin{array}{l}-0.00 \\
(0.00)\end{array}$ & $\begin{array}{l}-0.00 \\
(0.00)\end{array}$ & --- & $\begin{array}{l}0.00 \\
(0.03)\end{array}$ & $\begin{array}{l}0.01 \\
(0.03)\end{array}$ \\
\hline $\begin{array}{l}\text { Victim*Peer } \\
\text { problems }\end{array}$ & --- & $\begin{array}{c}0.00 \\
(0.01)\end{array}$ & $\begin{array}{c}0.00 \\
(0.01)\end{array}$ & -- & $\begin{array}{c}0.01 \\
(0.01)\end{array}$ & $\begin{array}{c}0.01 \\
(0.01)\end{array}$ & --- & $\begin{array}{l}-0.00 \\
(0.03)\end{array}$ & $\begin{array}{l}0.00 \\
(0.03)\end{array}$ & -- & $\begin{array}{c}0.00 \\
(0.00)\end{array}$ & $\begin{array}{c}0.00 \\
(0.00)\end{array}$ & --- & $\begin{array}{l}0.02 \\
(0.03)\end{array}$ & $\begin{array}{c}0.02 \\
(0.03)\end{array}$ \\
\hline
\end{tabular}


$\underline{\text { Females }}$

\begin{tabular}{|c|c|c|c|c|c|c|c|c|c|c|c|c|c|c|c|}
\hline Peer problems & $\begin{array}{l}-0.00 \\
(0.00)\end{array}$ & $\begin{array}{l}-0.00 \\
(0.00)\end{array}$ & $\begin{array}{l}-0.00 \\
(0.00)\end{array}$ & $\begin{array}{c}0.01 \\
(0.00)^{* *}\end{array}$ & $\begin{array}{l}0.01 \\
(0.01)\end{array}$ & $\begin{array}{l}-0.00 \\
(0.01)\end{array}$ & $\begin{array}{c}0.06 \\
(0.02)^{* *}\end{array}$ & $\begin{array}{c}0.13 \\
(0.07)\end{array}$ & $\begin{array}{l}0.08 \\
(0.06)\end{array}$ & $\begin{array}{l}-0.00 \\
(0.00)^{*}\end{array}$ & $\begin{array}{l}-0.01 \\
(0.00)^{*}\end{array}$ & $\begin{array}{l}0.00 \\
(0.00)\end{array}$ & $\begin{array}{c}-0.04 \\
(0.01)^{* *}\end{array}$ & $\begin{array}{c}-0.06 \\
(0.02)^{* *}\end{array}$ & $\begin{array}{l}-0.00 \\
(0.02)\end{array}$ \\
\hline $\begin{array}{l}\text { Bullying } \\
\text { involvement }^{a}\end{array}$ & & & & & & & & & & & & & & & \\
\hline Bully & --- & $\begin{array}{l}0.08^{*} \\
(0.03)\end{array}$ & $\begin{array}{l}0.07 * \\
(0.03)\end{array}$ & --- & $\begin{array}{l}0.08 \\
(0.04)\end{array}$ & $\begin{array}{l}0.06 \\
(0.04)\end{array}$ & --- & $\begin{array}{l}0.16 \\
(0.24)\end{array}$ & $\begin{array}{c}0.10 \\
(0.21)\end{array}$ & --- & $\begin{array}{l}-0.02 \\
(0.02)\end{array}$ & $\begin{array}{l}-0.01 \\
(0.02)\end{array}$ & --- & $\begin{array}{l}-0.17 \\
(0.14)\end{array}$ & $\begin{array}{l}-0.07 \\
(0.12)\end{array}$ \\
\hline Bully-victim & --- & $\begin{array}{l}-0.00 \\
(0.01)\end{array}$ & $\begin{array}{l}-0.00 \\
(0.01)\end{array}$ & --- & $\begin{array}{l}0.02 \\
(0.01)\end{array}$ & $\begin{array}{c}0.01 \\
(0.01)\end{array}$ & --- & $\begin{array}{r}0.08 \\
(0.07)\end{array}$ & $\begin{array}{l}0.06 \\
(0.07)\end{array}$ & --- & $\begin{array}{c}0.00 \\
(0.01)\end{array}$ & $\begin{array}{l}-0.00 \\
(0.01)\end{array}$ & --- & $\begin{array}{l}-0.02 \\
(0.06)\end{array}$ & $\begin{array}{l}0.02 \\
(0.06)\end{array}$ \\
\hline Victim & --- & $\begin{array}{l}0.00 \\
(0.01)\end{array}$ & $\begin{array}{l}-0.00 \\
(0.01)\end{array}$ & --- & $\begin{array}{l}-0.01 \\
(0.01)\end{array}$ & $\begin{array}{l}-0.02 \\
(0.01)\end{array}$ & --- & $\begin{array}{l}0.06 \\
(0.06)\end{array}$ & $\begin{array}{l}0.05 \\
(0.06)\end{array}$ & --- & $\begin{array}{l}-0.00 \\
(0.01)\end{array}$ & $\begin{array}{l}0.00 \\
(0.01)\end{array}$ & --- & $\begin{array}{l}0.06 \\
(0.05)\end{array}$ & $\begin{array}{l}0.07 \\
(0.05)\end{array}$ \\
\hline Interaction terms & & & & & & & & & & & & & & & \\
\hline $\begin{array}{l}\text { Bully*Peer } \\
\text { problems }\end{array}$ & --- & $\begin{array}{l}-0.04 \\
(0.02)^{*}\end{array}$ & $\begin{array}{c}-0.04 \\
(0.01)^{* *}\end{array}$ & --- & $\begin{array}{l}-0.05 \\
(0.02)^{*}\end{array}$ & $\begin{array}{l}-0.05 \\
(0.02)^{*}\end{array}$ & --- & $\begin{array}{l}-0.06 \\
(0.13)\end{array}$ & $\begin{array}{l}-0.07 \\
(0.12)\end{array}$ & --- & $\begin{array}{l}0.00 \\
(0.01)\end{array}$ & $\begin{array}{l}0.01 \\
(0.01)\end{array}$ & --- & $\begin{array}{l}-0.01 \\
(0.07)\end{array}$ & $\begin{array}{l}0.02 \\
(0.06)\end{array}$ \\
\hline $\begin{array}{l}\text { Bully-victim*Peer } \\
\text { problems }\end{array}$ & --- & $\begin{array}{l}0.00 \\
(0.00)\end{array}$ & $\begin{array}{c}0.01 \\
(0.00)\end{array}$ & --- & $\begin{array}{c}0.00 \\
(0.01)\end{array}$ & $\begin{array}{c}0.00 \\
(0.01)\end{array}$ & --- & $\begin{array}{l}-0.08 \\
(0.08)\end{array}$ & $\begin{array}{l}-0.07 \\
(0.07)\end{array}$ & --- & $\begin{array}{c}0.00 \\
(0.00)\end{array}$ & $\begin{array}{l}0.00 \\
(0.00)\end{array}$ & --- & $\begin{array}{l}0.02 \\
(0.03)\end{array}$ & $\begin{array}{l}-0.01 \\
(0.03)\end{array}$ \\
\hline $\begin{array}{l}\text { Victim*Peer } \\
\text { problems }\end{array}$ & --- & $\begin{array}{l}-0.00 \\
(0.00)\end{array}$ & $\begin{array}{l}-0.00 \\
(0.00)\end{array}$ & --- & $\begin{array}{c}0.00 \\
(0.01)\end{array}$ & $\begin{array}{c}0.01 \\
(0.01)\end{array}$ & --- & $\begin{array}{l}-0.11 \\
(0.07)\end{array}$ & $\begin{array}{l}-0.10 \\
(0.07)\end{array}$ & --- & 0.01 & 0.00 & --- & $\begin{array}{c}0.03 \\
(0.03)\end{array}$ & $\begin{array}{l}0.00 \\
(0.03)\end{array}$ \\
\hline
\end{tabular}

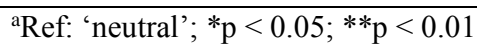

Model A: Cross-lagged effects on CGT measures at age 14 of peer problems at age 11, adjusted for autoregressive paths of CGT measures and peer problems

Model B: Cross-lagged effects on CGT measures at age 14 of peer problems at age 11, bullying involvement at age 11 and the interaction terms between peer problems and bullying involvement at age 11, adjusted for autoregressive paths of CGT measures and peer problems 
Model C: Same as Model B, with further adjustments for ethnicity, IQ, age at assessment, poverty, externalising problems, emotional problems, and maternal age and education

\section{Model fit}

Model A: CFI $=0.94 ;$ SRMR $=0.03 ;$ RMSEA $=0.03$

Model B: $\mathrm{CFI}=0.95 ;$ SRMR $=0.02 ;$ RMSEA $=0.03$

Model C: $\mathrm{CFI}=0.93 ;$ SRMR $=0.03 ;$ RMSEA $=0.05$ 
Table 4

Regression paths [unstandardised regression coefficients (standard errors)] to peer problems at age 14 from decision-making at age 11

Peer problems, age 14

Decision-making, age 11

Model A

Model B

Model C

\section{$\underline{\text { Males }}$}

Risk-taking

$-0.17(0.21)$

$-0.17(0.21)$

$-0.30(0.21)$

Delay aversion

$0.03(0.16)$

$0.03(0.17)$

$-0.06(0.16)$

Deliberation time

$0.05(0.03)$

$0.05(0.03)$

$0.05(0.03)$

Quality of decision-making

$-0.01(0.21)$

$0.00(0.20)$

$0.15(0.20)$

Risk adjustment

$-0.07(0.03)^{*}$

$-0.07(0.03)^{*}$

$-0.05(0.03)$

Females

Risk-taking

Delay aversion

Deliberation time

Quality of decision-making

Risk adjustment

$-0.05(0.17)$
$-0.05(0.11)$
$0.03(0.02)$
$-0.03(0.17)$
$-0.06(0.03)^{*}$

$-0.05(0.17)$

$-0.07(0.11)$

$0.02(0.02)$

$-0.02(0.17)$

$-0.06(0.03)^{*}$
$-0.07(0.16)$

$-0.13(0.11)$

$0.02(0.02)$

$0.13(0.17)$

$-0.02(0.03)$

$* p<0.05$

Model A: Cross-lagged effects on peer problems at age 14 of CGT decision-making measures at age 11, adjusted for autoregressive paths of CGT measures and peer problems

Model B: Cross-lagged effects on peer problems at age 14 of CGT decision-making measures at age 11 , bullying involvement at age 11 and the interaction terms between peer problems at age 11 and bullying involvement at age 11 , adjusted for autoregressive paths of CGT measures and peer problems

Model C: Same as Model B, with further adjustments for ethnicity, IQ, age at assessment, poverty, externalising problems, emotional problems, and maternal age and education

\section{Model fit}

Model A: CFI $=0.94 ;$ SRMR $=0.03 ;$ RMSEA $=0.03$

Model B: $\mathrm{CFI}=0.95 ;$ SRMR $=0.02 ; \mathrm{RMSEA}=0.03$

Model C: $\mathrm{CFI}=0.93 ;$ SRMR $=0.03 ;$ RMSEA $=0.05$ 

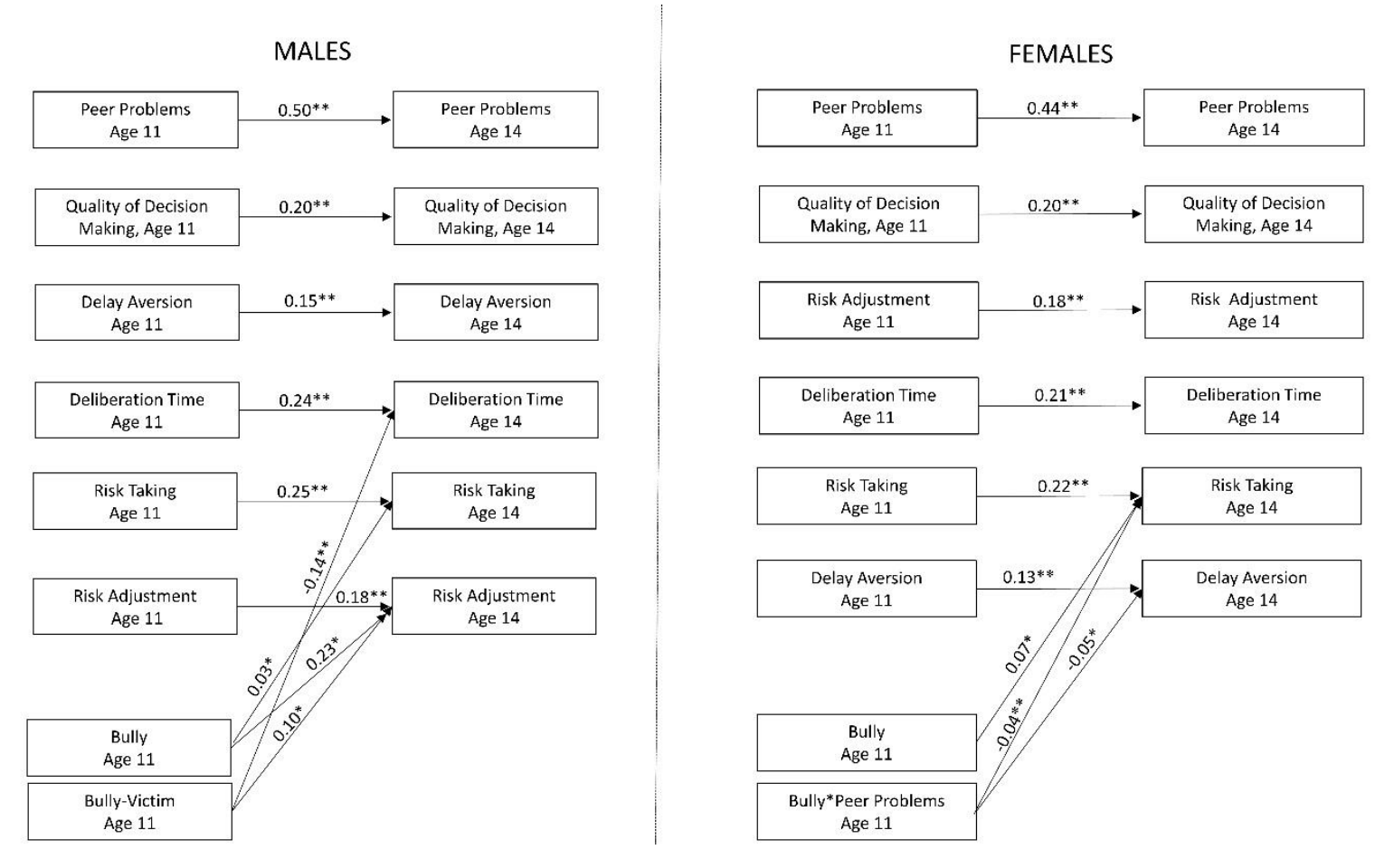

Figure 1. Significant paths (unstandardised regression coefficients) adjusted for ethnicity, IQ, age at assessment, poverty, externalising problems, emotional problems and maternal age and education, stratified by sex 
Table S1.

Unweighted means (SD) for decision-making and peer problems by sex and type of bullying involvement

Age 11

Neutral Bully Bully-Victim Victim p-value

Males

\section{Decision-making}

Delay aversion

Deliberation time

Overall proportion bet

Quality of decision-making

Risk adjustment

Risk-taking

Peer problems

$\begin{array}{ccccc}0.32(0.23) & 0.31(0.22) & 0.31(0.23) & 0.31(0.23) & 0.92 \\ 3210.87 & 3184.46 & 3268.17 & 3311.21 & 0.06 \\ (1149.82) & (1010.72) & (1430.77) & (1283.93) & \\ 0.53(0.15) & 0.55(0.15) & 0.53(0.14) & 0.52(0.15) & <0.001 \\ 0.80(0.16) & 0.79(0.16) & 0.80(0.17) & 0.80(0.17) & 0.54 \\ 0.65(1.00) & 0.56(1.01) & 0.67(1.03) & 0.67(1.03) & 0.23 \\ 0.58(0.15) & 0.60(0.15) & 0.58(0.16) & 0.57(0.16) & 0.001 \\ 1.04(1.41) & 1.28(1.51) & 1.66(1.88) & 1.67(1.83) & <0.001\end{array}$

\section{Females}

\section{Decision-making}

Delay aversion

Deliberation time

Overall proportion bet

Quality of decision-making

Risk adjustment

Risk-taking

Peer problems

$\begin{array}{ccccc}0.25(0.27) & 0.28(0.31) & 0.27(0.26) & 0.27(0.26) & 0.05 \\ 3321.84 & 3323.00 & 3384.75 & 3506.14 & <0.001 \\ (1340.90) & (1468.68) & (1313.03) & (1520.37) & \\ 0.44(0.16) & 0.49(0.16) & 0.46(0.15) & 0.44(0.16) & <0.001 \\ 0.81(0.17) & 0.78(0.17) & 0.80(0.17) & 0.80(0.17) & 0.16 \\ 0.67(1.07) & 0.50(1.16) & 0.61(0.99) & 0.62(1.05) & 0.12 \\ 0.48(0.17) & 0.53(0.17) & 0.50(0.16) & 0.48(0.17) & <0.001 \\ 0.95(1.29) & 1.34(1.49) & 1.52(1.78) & 1.50(1.71) & <0.001\end{array}$

Age 14

Males

Decision-making

Delay aversion

Deliberation time

Overall proportion bet

Quality of decision-making

Risk adjustment

Risk-taking

Peer problems

$\begin{array}{ccccc}0.28(0.20) & 0.30(0.20) & 0.27(0.20) & 0.28(0.20) & 0.31 \\ 2338.02 & 2275.89 & 2315.52 & 2415.63 & 0.03 \\ (900.03) & (813.91) & (937.11) & (1051.98) & \\ 0.51(0.14) & 0.52(0.13) & 0.51(0.13) & 0.50(0.14) & 0.03 \\ 0.89(0.12) & 0.88(0.13) & 0.89(0.12) & 0.89(0.13) & 0.81 \\ 1.06(0.96) & 1.05(1.02) & 1.17(0.96) & 1.13(0.99) & 0.004 \\ 0.55(0.15) & 0.57(0.14) & 0.56(0.14) & 0.54(0.14) & 0.02 \\ 1.55(1.64) & 1.66(1.69) & 1.88(1.95) & 2.15(2.03) & <0.001\end{array}$

\section{Females}

Decision-making
Delay aversion
Deliberation time
Overall proportion bet
Quality of decision-making
Risk adjustment
Risk-taking
Peer problems

\begin{tabular}{ccccc}
$0.26(0.23)$ & $0.30(0.25)$ & $0.27(0.23)$ & $0.25(0.23)$ & 0.05 \\
2295.95 & 2354.72 & 2313.17 & 2327.22 & 0.67 \\
$(834.52)$ & $(817.06)$ & $(942.77)$ & $(1046.20)$ & \\
$0.45(0.14)$ & $0.47(0.14)$ & $0.45(0.13)$ & $0.44(0.14)$ & 0.002 \\
$0.88(0.13)$ & $0.84(0.16)$ & $0.88(0.13)$ & $0.89(0.13)$ & 0.001 \\
$0.88(0.97)$ & $0.78(0.98)$ & $0.95(0.92)$ & $0.93(0.97)$ & 0.08 \\
$0.48(0.14)$ & $0.50(0.15)$ & $0.49(0.14)$ & $0.47(0.15)$ & 0.002 \\
$1.35(1.51)$ & $1.67(1.53)$ & $1.86(1.85)$ & $1.95(1.90)$ & $<0.001$ \\
\hline
\end{tabular}


Table S2

Unweighted means (SD) for decision-making and peer problems at age 14 by sex and type of bullying involvement at age 11

Males

Neutral Bully Bully-Victim Victim p-value

Decision-making

Delay aversion

Deliberation time

Overall proportion bet

Quality of decision-making

Risk adjustment

Risk-taking

Peer problems

$\begin{array}{ccccc}0.27(0.20) & 0.26(0.18) & 0.29(0.20) & 0.28(0.21) & 0.10 \\ 2315.17 & 2418.81 & 2318.94 & 2393.90 & 0.04 \\ (909.12) & (942.18) & (922.23) & (999.14) & \\ 0.51(0.14) & 0.53(0.14) & 0.51(0.13) & 0.50(0.14) & 0.01 \\ 0.89(0.12) & 0.87(0.13) & 0.88(0.13) & 0.88(0.13) & 0.24 \\ 1.10(0.96) & 1.08(0.96) & 1.12(0.99) & 1.12(1.00) & 0.83 \\ 0.55(0.14) & 0.58(0.14) & 0.56(0.14) & 0.55(0.15) & 0.01 \\ 1.51(1.65) & 1.63(1.57) & 1.96(2.00) & 1.97(1.96) & <0.001\end{array}$

\section{Females}

\section{Decision-making}

Delay aversion

Deliberation time

Overall proportion bet

Quality of decision-making

Risk adjustment

Risk-taking

$\begin{array}{cc}0.26(0.23) & 0.28(0.24) \\ 2260.35 & 2316.03 \\ (793.90) & (1160.77) \\ 0.45(0.14) & 0.47(0.12) \\ 0.88(0.13) & 0.87(0.13) \\ 0.91(0.95) & 0.91(1.04) \\ 0.48(0.14) & 0.51(0.13) \\ 1.36(1.53) & 1.61(1.54)\end{array}$

\begin{tabular}{ccc}
$0.28(0.23)$ & $0.26(0.22)$ & 0.04 \\
2324.67 & 2326.93 & 0.07 \\
$(918.12)$ & $(895.70)$ & \\
$0.45(0.13)$ & $0.44(0.14)$ & 0.01 \\
$0.88(0.13)$ & $0.89(0.13)$ & 0.44 \\
$0.87(0.94)$ & $0.96(0.98)$ & 0.10 \\
$0.49(0.14)$ & $0.47(0.14)$ & 0.01 \\
$1.82(1.77)$ & $1.82(1.86)$ & $<0.001$ \\
\hline
\end{tabular}

Peer problems

$1.36(1.53) \quad 1.61(1.54)$

$1.82(1.77)$

$1.82(1.86)$ 